\title{
АНАЛИЗ АНАТОМИЧЕСКИХ ОРИЕНТИРОВ В ЦЕЛЯХ ПРИМЕНЕНИЯ РЕГИОНАРНОЙ АНЕСТЕЗИИ ПРИ СТОМАТОЛОГИЧЕСКИХ ВМЕШАТЕЛЬСТВАХ И ОРОФАЦИАЛЬНОЙ ХИРУРГИИ У ЛАБОРАТОРНЫХ И ДЕКОРАТИВНЫХ КРОЛИКОВ
}

\author{
Мозгова Анастасия Юрьевна \\ Аспирант \\ Научный руководитель: Селезнев Сергей Борисович \\ Доктор ветеринарных наук, профессор \\ Российский Университет Дружбы Народов
}

Аннотация Регионарная анестезия является основным методом обезболивания при орофациальных стоматологических и хирургических вмешательствах у людей и мелких домашних животных. Тем не менее, соответствующие методы обезболивания ветвей нижнечелюстного и верхнечелюстного нервов у лабораторных и декоративных кроликов не описаны.

Цель работы заключалась в изучении особенностей макроскопического строения черепа экспериментальных животных - кроликов, которые в литературе представлены поверхностно. Прикладная анатомия - один из принципов клинической и хирургической практики; так как это позволяет клиницисту визуализировать детали структур, относящиеся к рассматриваемому случаю. Точно так же направление черепных нервов и их ходы от различных отверстий черепа имеют клиническое значение при регионарной анестезии области головы в хирургических целях во время лечения травм головы и удаления зубов.

Ключевые слова: анатомия, регионарная блокада, нервы, анальгезия, кролик.

\section{ANALYSIS OF ANATOMICAL LANDMARKS FOR THE USE REGIONAL ANESTHESIA FOR DENTISTRY AND OROFACIAL SURGERY IN LABORATORY AND DECORATIVE RABBITS}




\section{ПЕРЕДОВОЕ РАЗВИТИЕ СОВРЕМЕННОЙ НАУКИ КАК ДРАЙВЕР РОСТА ЭКОНОМИКИ И СОЦИАЛЬНОЙ СФЕРЫ}

Abstract Regional anesthesia is a commonly used adjunct to orofacial dental and surgical procedures in companion animals and humans. However, appropriate techniques for anesthetizing branches of the mandibular and maxillary nerves have not been described for laboratory and decorative rabbits.

The aim of the work was to study the features of the macroscopic structure of the skull of experimental animals - rabbits, which are presented superficially in the literature. Anatomy is one of the principles of clinical and surgical practice; as it allows the clinician to visualize the details of structures related to the case in question. Similarly, the direction of cranial nerves and their codes from various openings of the skull are of clinical importance for regional anesthesia of the head area for surgical purposes during the treatment of head injuries and tooth extraction.

Key words: anatomy, block anesthesia, nerves, analgesia, rabbit.

\section{Введение}

Лабораторные кролики - один из наиболее распространенных видов заичьих, обитающих в исследовательских центрах по всему миру. Лечение стоматологических заболеваний и орофациальных травм является частью рутинной ветеринарной помощи данным животным. Более того, кролики используются в качестве моделей стоматологических заболеваний, включая исследования, связанные с хирургическими манипуляциями. Адекватная анальгезия во время болезненных процедур имеет решающее значение для обеспечения наилучшего качества жизни исследуемых кроликов и является как ключевым компонентом хорошей ветеринарной помощи.

Для большинства рутинных операций по удалению зубов и ушиванию мелких ран местные анестетики могут быть эффективно использованы в качестве местной инфильтрации, применяемой рядом с операционным полем. Однако некоторые оперативные вмешательства требуют использования региональных блокад.

Во-первых, поскольку нижнечелюстная кость является более плотной, чем верхнечелюстная кость, анестетики не проникают в нижнечелюстную кость так же эффективно, как в верхнечелюстную кость. По этой причине регионарные блокады являются более предпочтительными для сложных операций, чем местная инфильтрация. Во-вторых, местные анестетики могут быть не так эффективны при введении в воспаленные ткани по сравнению с невоспаленными тканями. Таким образом, при работе в зонах с тяжелыми заболеваниями пародонта или инфекциями более предпочтительна регионарная 


\section{ПЕРЕДОВОЕ РАЗВИТИЕ СОВРЕМЕННОЙ НАУКИ КАК ДРАЙВЕР РОСТА ЭКОНОМИКИ И СОЦИАЛЬНОЙ СФЕРЫ}

блокада нерва в области, удаленной от места операции. В-третьих, обширная орофациальная травма или множественные удаления зубов могут потребовать локальной инфильтрации препарата превышающей допустимые лимиты дозировки анестетика; регионарные блокады обезболивают большие области относительно небольшим количеством анестетика, избегая возможной системной токсичности. В-четвертых, при сложном удалении зубов с большими глубокими корнями, таких как клыки верхней челюсти, можно воспользоваться блокадой всей пораженной области. В заключение, при обеспечении анальгезии для биопсии или удаления орофациальных новообразований необходима инъекция в область удаленную от места хирургического вмешательства, чтобы избежать посева опухоли при введении.

Были описаны методы регионарной блокады верхнечелюстного нерва, и соответственно его ветвей: большого небного нерва, носонебного нерва и подглазничного нерва. Описаны методы регионарной блокады нижнечелюстного нерва, и соответственно его ветвей: нижнего альвеолярного нерва, ментального (или подбородочного) нерва, языкового нерва и длинного щечного нерва. Местная анестезия нижнечелюстных и верхнечелюстных нервов у лабораторных кроликов может быть выполнена слепым методом и является практичным и эффективным способом для обеспечения максимального комфорта животных во время потенциально болезненных орофациальных процедур.

\section{Материалы и методы}

Были изучены исследования, основанные на анализе рентгенологических и КТ исследованиях черепов кроликов.

Общие анатомические результаты:

Череп лепорид (кроликов и зайцев) сильно трансформирован и характеризуется выраженным изгибом дорсальной стороны черепа и вентральным изгибом лицевой области (т. е. наклоном лица).

Задняя затылочная поверхность черепа образована составной затылочной костью (слияние надзатылочной, парных боковых экзозатылочной и вентральной базиозатылочной кости), она пронизана большим затылочным отверстием, которое с каждой стороны несет затылочные мыщелки, в мыщелковой ямке имеется подъязычный канал. Яремный отросток затылочной кости, плотно прикреплен к барабанной булле. Имеется наружный затылочный гребень (рис.1.А). 


\section{ПЕРЕДОВОЕ РАЗВИТИЕ СОВРЕМЕННОЙ НАУКИ КАК ДРАЙВЕР РОСТА ЭКОНОМИКИ И СОЦИАЛЬНОЙ СФЕРЫ}

Дорсальная поверхность черепа образована дорсальной поверхностью затылочной, малой межтеменной, парной теменной, парной лобной и парной носовой костей. Дорсальная поверхность черепа отделена от затылочной поверхности отчетливым и острым затылочным гребнем. Неглубокий внешний сагиттальный гребень, лежащий от затылочного гребня до половины расстояния лобных костей. Лобные кости имеют передние и задние дорсолатерально расположенные надглазничные отростки, надглазничное отверстие отсутствует.

На боковой поверхности каудально виден перевернутый конус сосцевидного отростка периотической кости на каудолатеральной стороне черепа, наружный слуховой проход представляет собой короткую широкую костную трубку с большим отверстием, направленным каудодорсально. Височная ямка в целом непрерывна с орбитальной. Глазницы большие в соответствии с размером черепа.

Лицевой скелет кролика удлинен с выраженной острой диастемой. Резцовые кости имеют направленные дорсально прочные дорсальные отростки, проходящие над верхней челюстью. В вертикальной пластинке верхней челюсти имеется большое подглазничное отверстие, расположенное выше и перед самым передним премолярным зубом. На внешней поверхности верхней челюсти имеется множество мелких отверстий (фенестрированных).

Вентральная часть черепа образована медиально расположенными базиокципитальными, базисфеноидными и пресфеноидными костями, расположенными ростральнее большого затылочного отверстия, а вентральная часть продолжается парной небной костью, каудальные концы которой зазубрены и сочленяются с двумя пластинками крыловидного отростка алисфеноидной кости. Твердое небо образовано небными костями, которые можно видеть медиальнее альвеолярных отростков верхней челюсти, вентральных частей верхней челюсти и резцовой кости, небное отверстие, расположенное рядом с первым коренным зубом, ростральная часть твердого неба, пронизанная длинными и узкими парными резцовыми отверстиями, которые проходят через среднюю линию в их каудальной трети (рис.1.Б). 

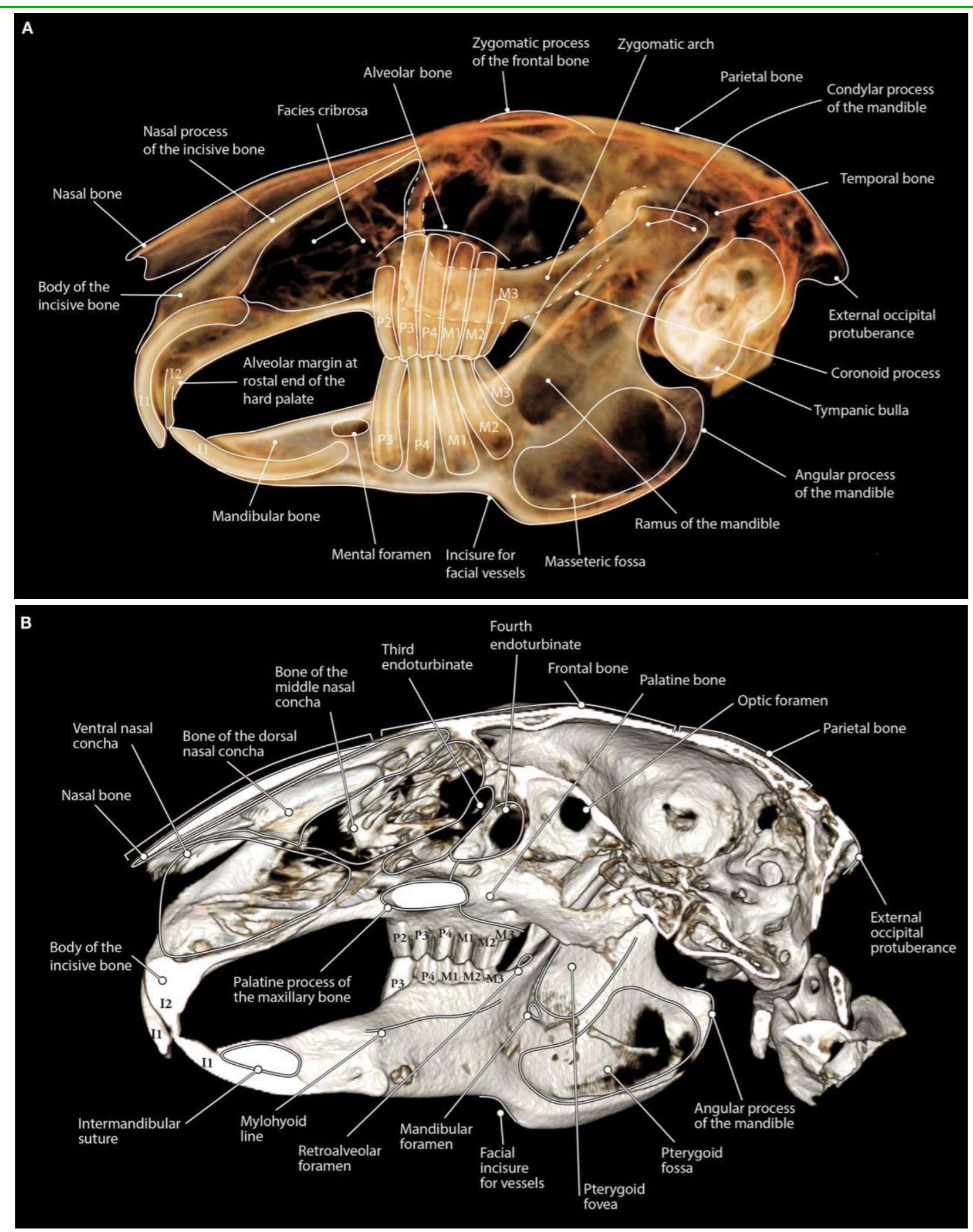

Рис.1. (А) Челюстно-лицевая анатомия кролика, видимая при просмотре 3D-визуализации зубов (отображение незатененной поверхности) по данным КЛКТ. Отображается боковой аспект левой стороны черепа с обрезанной правой стороной изображения. Обратите внимание, как скуловая дуга 


\section{ПЕРЕДОВОЕ РАЗВИТИЕ СОВРЕМЕННОЙ НАУКИ КАК ДРАЙВЕР РОСТА ЭКОНОМИКИ И СОЦИАЛЬНОЙ СФЕРЫ}

накладывается на верхние премоляры и коренные зубы. (Б) Челюстно-лицевая анатомия кролика в режиме трехмерной объемной визуализации в режиме кости (отображение заштрихованной поверхности) по данным КЛКТ. Левая половина черепа обрезана, чтобы можно было видеть медиальную часть черепа. Обратите внимание на форму небного отростка верхнечелюстной кости, поскольку эту структуру можно увидеть наложенной на второй, третий и четвертый премоляры верхней челюсти на панорамных изображениях.

\section{Результаты}

Исходя из изученных данных и анализа научной литературы, можем выделить основные виды региональных блокад лицевых нервов, допустимых к использованию при стоматологических вмешательствах и орофациальной хирургии у лабораторных и декоративных кроликов.

Подглазничный нерв - это ветвь верхнечелюстного нерва, которая выходит из черепа через подглазничное отверстие, расположенное вдоль костного гребня чуть ниже глаза. Подглазничная блокада используется для обезболивания при экстракции резцов верхней челюсти. Блокада подглазничного нерва проводится вблизи с подглазничным отверстием. Ориентиром служит подглазничное отверстие, расположенное рострально от медиального угла глаза на уровне первого щечного зуба. Игла вводится в подглазничное отверстие под углом от медиального угла глаза, затем проводится аспирационная проба и вводится анестетик.

Верхнечелюстной нерв обеспечивает чувствительность боковой части носа, нижнего века, верхней губы, верхнего нёба, зубам верхней челюсти и десне верхней челюсти. Блокада верхней челюсти используется для обезболивания щечных зубов верхней челюсти и окружающих тканей. Подглазничное отверстие служит ориентиром. Игла вводится под углом к медиальному углу глаза, параллельно линии окклюзии щечных зубов. В этом случае у крупных кроликов игла вводится глубже в подглазничный канал (до 12 см), затем проводится аспирационная проба и вводится анестетик.

Подбородочный нерв выходит из нижней челюсти в подбородочном отверстии и иннервирует мягкие ткани нижней челюсти, прилегающие к клыкам и резцам. Блокада подбородочного нерва используется для обезболивания резцов нижней челюсти. Блокада проводится в части нижнечелюстного нерва, выходящего через подбородочное отверстие. Игла вводится со стороны десны в подбородочное отверстие, затем проводится аспирационная проба и вводится анестетик. 


\section{ПЕРЕДОВОЕ РАЗВИТИЕ СОВРЕМЕННОЙ НАУКИ КАК ДРАЙВЕР РОСТА ЭКОНОМИКИ И СОЦИАЛЬНОЙ СФЕРЫ}

Нижнечелюстной нерв выходит из черепа через овальное отверстие и идет рострально по медиальной стороне височно-нижнечелюстного сустава. Нижнечелюстной нерв обеспечивает чувствительность твердых и мягких тканей нижней челюсти (включая зубы, слизистую оболочку щек и нижних губ), языка, части кожи головы и слизистой внутрикостной части наружного слухового прохода. Нижнечелюстная блокада используется для обезболивания щечных зубов нижней челюсти и окружающих тканей. Блокада нижнечелюстная ветвь тройничного нерва проводится у входа в нижнечелюстное отверстие. Осуществляется через интраоральный доступ.

Есть и альтернатива этой блокаде. Игла вводится с медиальной стороны ветви нижней челюсти на 2-5 мм дистальнее 3-го щечного зуба. Она вводится вдоль нижней челюсти по направлению к точке посередине между дистальной частью моляра нижней челюсти и вентральной точкой нижней челюсти.

\section{Заключение}

Регионарные методы используются у экзотических животных для улучшения периоперационной анальгезии, а также для уменьшения потребности в системных анальгетиках во время и после инвазивных операций. Многочисленные местные и региональные блокады доказали свою эффективность, что дает врачу широкие возможности для применения этих блокад на практике. К сожалению, у местной анестезии есть свои недостатки и осложнения. Для местной анестезии области головы у грызунов и зайцеобразных используются слепые методики, выполнение которых не может обеспечить стопроцентной эффективности. Кроме того, существует риск внутривенного введения анестетика, что в некоторых случаях может привести к летальному исходу. Несмотря на это, мы должны стремиться обеспечить качественную анестезиологическую поддержку любому пациенту, и в этом случае использование местной анестезии может быть эффективным инструментом для достижения этой цели. Все региональные блокады, описанные в данной статье, могут быть эффективно выполнены с использованием знаний анатомии экзотических животных, хороших навыков пальпации и соответствующей техники инъекции (т.е. мягкого введения иглы, аспирации перед инъекцией). 


\section{Список литературы}

1. Yong-Di L, Zheng-Long T, Jian-Qin T, Dong-Xiang W, You-Li C. Anatomy of the Inferior Alveolar Nerve in Rabbits and its Block Anesthesia // Int J Oral Dent Health - 2018. - C. 1-4.

2. Salih K.M. Gross anatomical and morophmetrical studies to the skull bones of the local rabbit (oryctohguscuniculus) // Basrah journal of veterinary research - 2013. - № 2. - C. 269-270.

3. Normal Dentition, G. G. Riggs, Boaz Arzi, Derek D. Cissell, David C. Hatcher, Philip H. Kass, Amy Zhen and Frank J. M. Verstraete. Clinical Application of Cone-Beam Computed Tomography of the Rabbit Head: Part 1 // Frontiers in veterinary science -2016 . - C. 4.

4. Ali Louei Monfared. Applied Anatomy of the Rabbit's Skull and its Clinical Application during regional anesthesia // Global Veterinaria - 2013. - C. 653-656. 